\title{
State-of-the-Art of Endomyocardial Biopsy on Acute Myocarditis and Chronic Inflammatory Cardiomyopathy
}

\author{
Enrico Ammirati ${ }^{1}$ - Andrea Buono ${ }^{2} \cdot$ Francesco Moroni $^{3} \cdot$ Lorenzo Gigli $^{1} \cdot$ John R. Power $^{4} \cdot$ Michele Ciabatti $^{5}$. \\ Andrea Garascia ${ }^{1} \cdot$ Eric D. Adler $^{4} \cdot$ Maurizio Pieroni $^{5}$
}

Accepted: 10 February 2022 / Published online: 24 February 2022

(c) The Author(s), under exclusive licence to Springer Science+Business Media, LLC, part of Springer Nature 2022

\begin{abstract}
Purpose of Review Histologic evidence of myocardial inflammatory infiltrate not secondary to an ischemic injury is required by current diagnostic criteria to reach a definite diagnosis of myocarditis. Endomyocardial biopsy (EMB) is therefore often indicated for the diagnosis of myocarditis, although it may lack sufficient sensitivity considering the limited possibility of myocardial sampling. Improving the diagnostic yield and utility of EMB is of high priority in the fields of heart failure cardiology and myocarditis in particular. The aim of the present review is to highlight indications, strengths, and shortcomings of current EMB techniques, and discuss innovations currently being tested in ongoing clinical studies, especially in the setting of acute myocarditis and chronic inflammatory cardiomyopathy.

Recent Findings EMB provides unique diagnostic elements and prognostic information which can effectively guide the treatment of myocarditis. Issues affecting the diagnostic performance in the setting of acute myocarditis and chronic inflammatory cardiomyopathies will be discussed in this review in the light of recent expert consensus documents on the management of these conditions and on indication to EMB. Recent innovations using electroanatomic mapping (EAM)-guided EMB and fluoroscopic-guided EMB during temporary mechanical circulatory support have improved the utility of the procedure.

Summary EMB remains an important diagnostic test whose results need to be interpreted in the context of (1) clinical pretest probability, (2) timing of sampling, (3) quality of sampling (4) site of sampling, (5) histologic type of myocarditis, and (6) analytic methods that are applied. Herein we will review these caveats as well as perspectives and innovations related to the use of this diagnostic tool.
\end{abstract}

Keywords Endomyocardial biopsy $\cdot$ Acute myocarditis $\cdot$ Inflammatory cardiomyopathy $\cdot$ Viral search $\cdot$ Histology $\cdot$ Electroanatomic mapping

\section{Abbreviations}

AHA

AM

CMRI

American Heart Association

Acute myocarditis

Cardiac magnetic resonance imaging

Enrico Ammirati and Andrea Buono equally contributed to the realization of this manuscript

This article is part of the Topical Collection on Myocardial Disease

Enrico Ammirati

enrico.ammirati@ospedaleniguarda.it

1 De Gasperis" Cardio Center and Transplant Center, Niguarda Hospital, ASST Grande Ospedale Metropolitano Niguarda, Piazza Ospedale Maggiore, 3, 20162 Milan, Italy

2 Interventional Cardiology Unit, Cardiovascular Department, Fondazione Poliambulanza, Brescia, Italy
COR Class of recommendation

DNA Deoxyribonucleic acid

EAM Electroanatomic mapping

EMB Endomyocardial biopsy

ESC European Society of Cardiology

GCM Giant cell myocarditis

HF Heart failure

Hs-Tn High-sensitivity troponin

ICI Immune checkpoint inhibitors

3 Vita-Salute San Raffaele University and Hospital, Milan, Italy

4 Division of Cardiology, Department of Medicine, University of California San Diego, San Diego, CA, USA

5 Cardiovascular Department, ASL8 Arezzo San Donato Hospital, Arezzo, Italy 


$\begin{array}{ll}\text { Infl-CMP } & \text { Inflammatory cardiomyopathy } \\ \text { LOE } & \text { Level of evidence } \\ \text { LGE } & \text { Late gadolinium enhancement } \\ \text { LV } & \text { Left ventricular/ventricle } \\ \text { PVB19 } & \text { Parvovirus B19 } \\ \text { RNA } & \text { Ribonucleic acid } \\ \text { RV } & \text { Right ventricular/ventricle } \\ \text { VA-ECMO } & \text { Venous-arterial extracorporeal membrane } \\ & \text { oxygenator }\end{array}$

\section{Introduction}

Myocarditis is an inflammatory disease of the myocardium which commonly presents with chest pain, dyspnea, palpitations, or syncope [1•]. Myocarditis is characterized by a large spectrum of clinical manifestations, ranging from an uncomplicated presentation with normal cardiac function to cardiogenic shock due to severe ventricular hypokinesis (i.e., fulminant myocarditis) or complicated by malignant ventricular arrhythmias [1•]. In about $25 \%$ of cases, it is complicated by reduced left ventricular (LV) systolic function, acute heart failure (HF), conduction abnormalities, or ventricular arrhythmias [1•]. The prevalence is heterogeneous, but in the age between 20 and 44 years, it has been recently estimated that the incidence of myocarditis is 6.1 per 100,000 in men and 4.4 per 100,000 in women [2]. Myocardial injury can be due to heterogeneous causes but is most frequently due to infective pathogens, especially

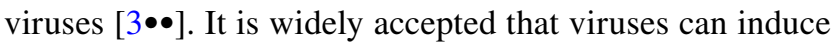
myocarditis, both through a direct myocardial injury and/ or triggering abnormal hyperactivity of the immune system

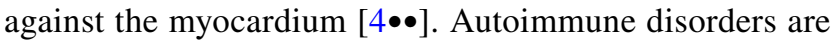
among other common causes of myocarditis, like exposure to toxic, or drugs (i.e., the new anticancer class of immune checkpoint inhibitors (ICI) [5, 6]). A genetic susceptibility has been more recently recognized $[7 \bullet, 8,9]$. The term myocarditis encompasses both acute myocarditis (AM) and chronic inflammatory cardiomyopathy (infl-CMP). These conditions differ in terms of clinical presentation, diagnostic yields of imaging-based and invasive tools, and treatment strategies [10]. The term AM refers to a disorder in which cardiac symptoms lasting less than 1 month, usually associated with chest pain with significant increased levels of high-sensitivity troponin (hs-Tn). Evidence of edema at cardiac magnetic resonance imaging (CMRI) [11] or a florid inflammatory myocardial infiltrate when an endomyocardial

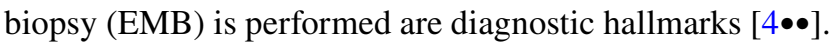
Chronic infl-CMP indicates a persistent/chronic inflammatory condition lasting more than 1 month with a clinical phenotype of hypokinetic myocardium that can be associated with increased risk for arrhythmia. Patients with chronic infl-CMP generally present with signs and symptoms of HF, and only mildly increased levels of hs-Tn. CMRI can have reduced diagnostic accuracy since edema may not be present or readily identifiable $[4 \bullet \bullet, 10,12]$. Histologically, infl-CMP is characterized by myocyte abnormalities, focal, or diffuse

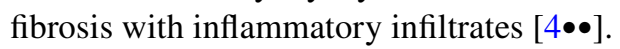

Diagnostic challenges concerning myocarditis have long been known. Jean-Baptiste de Sénac [13], famous French physician operating during the eighteenth century, wrote: "Cardiac inflammation is difficult to diagnose, and even if diagnosed, can we treat it effectively?" Almost three centuries later, these words still sound contemporary. To reach a definite diagnosis of myocarditis, current expert consensus documents require histologic evidence of myocardial inflam-

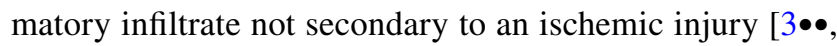
$14,15 \bullet \bullet$. Historically, active myocarditis was defined by the presence of infiltrating inflammatory mononucleated cells and myocyte necrosis - with or without fibrosis (Dallas criteria) [16]. Currently, the only way to identify and characterize the inflammatory cell infiltrate is by performing an EMB. Transvenous EMB was first performed by Sakakibara and Konno in 1962 [17] using a technique similar to today's, with minor changes related to the adoption of modern single-use bioptomes with smaller jaws $[18 \bullet, 19]$. However, EMB use has decreased over time, likely due to its invasive nature [20, $21 \bullet$. Nevertheless, it provides unique useful information for diagnosis, prognosis, and treatment of myocarditis [22, 23]. Since EMB remains a cornerstone in myocarditis diagnostic workup, clinicians should be aware that the diagnostic performance of EMB depends on many aspects (Fig. 1) and only its rational use can ensure an optimal yield. Issues that affect the diagnostic performance in the setting of AM and chronic infl-CMP will be discussed in this review, including (1) clinical pre-test probability, (2) timing of sampling, (3) technical issue of sampling, (4) site of sampling, (5) histologic type of myocarditis, and (6) analytic methods that are applied. Based on these concepts, we will weigh the pros and cons of EMB and discuss future directions related to the use of this diagnostic tool.

\section{Who Should Be Referred to EMB?}

EMB is indicated based on clinical signs, symptoms, and patient history that support the diagnosis of AM or chronic infl-CMP [4••]. In fact, the higher is the pre-test likelihood, the more informative is the EMB [24•]. In most cases, we cannot verify the validity of negative EMB findings. Only a few studies on a post-mortem or explanted hearts compared biopsy specimens to the histologic analysis of the whole heart $[25,26]$. Thus, it should be more appropriate to define EMB as a reference standard rather than a gold standard for the diagnosis of myocarditis. The integration of all available information, such as personal history, clinical presentation, 


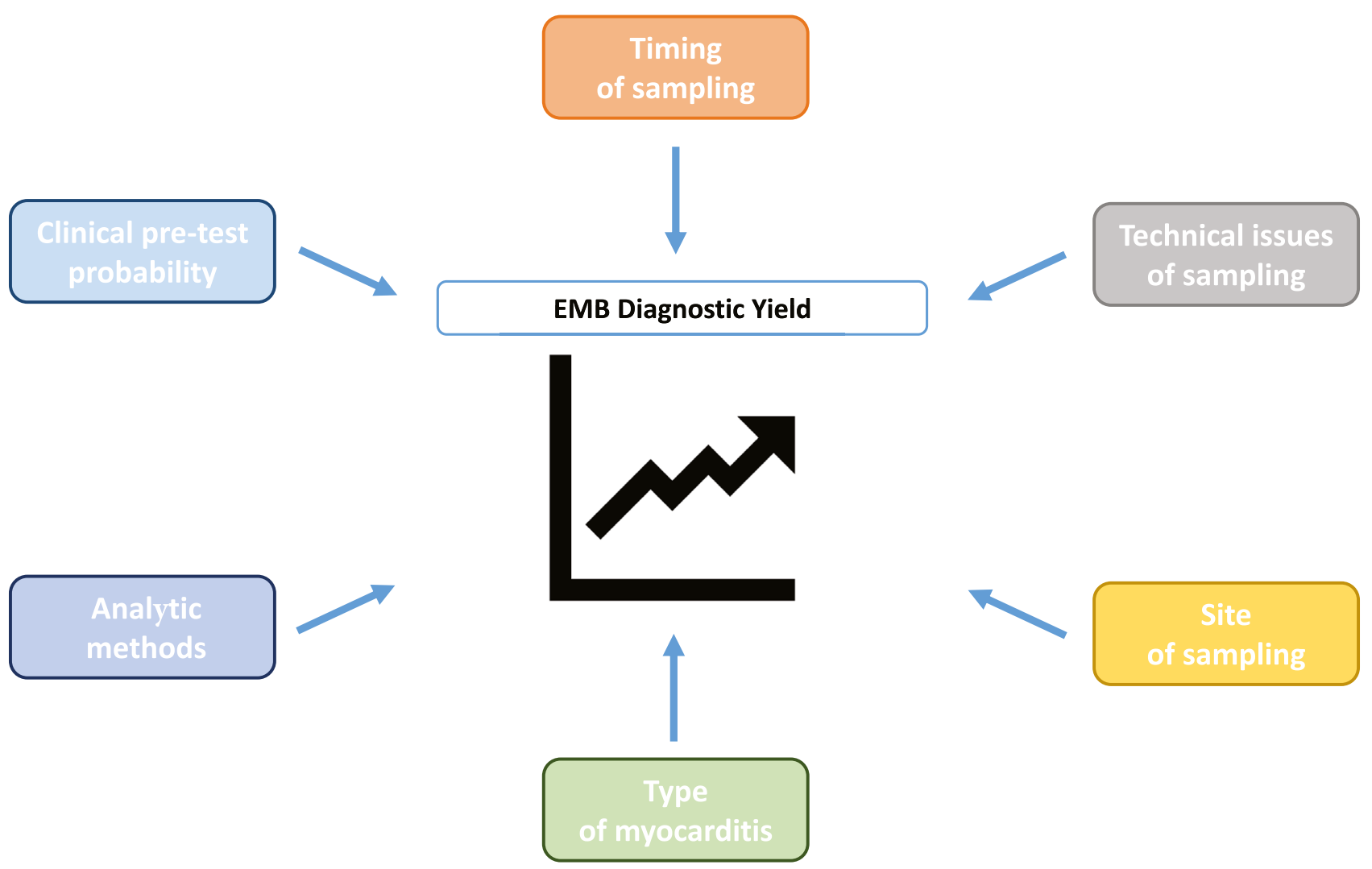

Fig. 1 Aspects influencing endomyocardial biopsy (EMB) diagnostic performance

age, presence of cardiovascular risk factors, exclusion of other differential diagnosis, laboratory tests (i.e., troponins, C-reactive proteins), electrocardiogram (ECG), echocardiogram in combination with CMRI, and/or EMB can allow the identification of myocarditis with higher accuracy than any single exam, including histology $[27,28]$. Furthermore, the higher the extent of the inflammatory infiltrate, the higher the likelihood of a diagnostic EMB. For this reason, fulminant myocarditis, that is generally associated with diffuse inflammatory infiltrate can be identified with a higher probability than AM with preserved LV ejection fraction in which focal infiltrates are expected [24•,29]. According to the 2013 position statement of the European Society of Cardiology (ESC) Working Group on Myocardial and Pericardial Diseases [14], all patients with suspected myocarditis should undergo EMB.

Nevertheless, the prognosis varies according to the presentation [30••, 31]. For these reasons, two American Heart Association (AHA) scientific statements recommend EMB as first-line diagnostic modality (class of recommendation (COR) I, level of evidence (LOE) B) in every unexplained acute cardiomyopathy complicated by hemodynamic instability requiring inotropic or mechanical circulatory support, Mobitz type 2 II or III degree atrioventricular block, sustained or symptomatic ventricular tachycardia, or failure to respond to medical therapy within $1-2$ weeks $[30 \bullet \bullet, 32]$. In all other cases, CMRI can be considered as the first modality to confirm/exclude the diagnosis (COR II, LOE C).

The AHA indications have been validated in a large retrospective analysis that assessed 851 patients with unexplained HF [33••]. Specifically, Bennett et al. found that EMB diagnostic yield was the highest when the suspicion of myocarditis is high, namely when there is new-onset HF (within 2 weeks) with normal or dilated LV and hemodynamic compromise. In this clinical scenario, EMB has a $39 \%$ diagnostic ability to identify the cause of new-onset HF and can change the clinical course in $28 \%$ of cases. The clinical impact was related to the fact that in most cases steroids were administered or discontinued as a consequence of EMB results. In the case of HF associated with dilated cardiomyopathy of any duration associated with allergic reaction and/or eosinophilia, EMB has a 33\% diagnostic yield and can change the clinical course in $33 \%$ of cases. Finally, in the scenario of HF onset between 2 weeks and 3 months with LV dilation and ventricular arrhythmias or II/III degree atrioventricular block or failure to respond to usual care within 1 to 2 weeks of therapy, EMB has 21\% diagnostic yield and can change the clinical course in $28 \%$ of patients [33••]. In another series of 23 patients who undergo EMB for cardiogenic shock needing venous-arterial extracorporeal 
membrane oxygenator (VA-ECMO) collected in 30 years from 1990 and 2020, EMB led to a histologic diagnosis in up to $78.3 \%$ of the patients, which consisted primarily of patients with myocarditis (73.9\%) [24•]. On the other hand, the relatively low diagnostic yield of EMB and the good prognosis of patients presenting with chest pain only makes EMB likely unnecessary in most cases of AM [1•]. This concept challenges the 2013 ESC position statement, but it is in accordance with AHA scientific statements and most national expert consensus documents [34-37]. It must be considered that EMB in the 23 patients requiring VA-ECMO was associated with a relatively high rate of significant complications in up to $26.1 \%$ associated mainly with sustained ventricular tachycardia and need of resuscitation (13.0\%) [24•]. In the control group of 125 patients who underwent an unplanned admission due to acute HF, the rate of significant EMB complications was $8.0 \%$, which was significantly lower $[24 \bullet]$.

In two recent international expert consensus documents, it has been proposed to expand the indications to EMB beyond AHA scientific statements, in particular in the following settings: (1) myocarditis in the setting of ICI where an appropriate diagnosis has implications for a patient receiving additional cancer therapy and where CMRI diagnostic yield is unknown and (2) AM or suspected chronic infl-CMP with persistent/relapsing release of myocardial necrosis markers, especially if associated with suspected/known autoimmune disorders for therapeutic implications (Table 1, and Fig. 2) $[4 \bullet \bullet, 15 \bullet \bullet$. The HF Association of the ESC/HF Society of America/Japanese HF Society position statement also includes the indication to perform EMB for dilated cardiomyopathy that has recent onset HF, moderate-to-severe LV

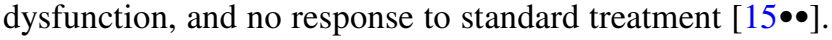

In new scenarios of suspected AM due to coronavirus disease 2019 (COVID-19) [38], or after mRNA COVID-19 vaccine $[39,40]$, the indications still follow the AHA scientific statement.

In conclusion, it is reasonable to consider CMRI first in cases of the uncomplicated presentation without more than mild cardiac systolic dysfunction. In patients with CMRI supporting an inflammatory myocardial disease with moderate LV systolic dysfunction without HF, EMB may be justified as it has the potential to confirm and define the type of inflammatory infiltrate before starting an immunosuppressive treatment.

\section{Time-Performance Relationship: Is Timing of Sampling Crucial?}

Most of the time, the acute phase of myocarditis resolves spontaneously without clinically relevant residual damage $[4 \bullet \bullet, 41]$. On the other hand, persistent inflammatory stimuli can be the pathogenic mechanism involved in the progression to chronic infl-CMP. Therefore, dilated cardiomyopathy may be the consequence of a long-standing inflammatory-mediated damage to the heart (i.e., chronic infl-CMP) [10]. The time from the onset of illness to EMB is one of the major determinants of diagnostic performance. Dec et al. showed that the rate of positive biopsies was $89 \%$ when exams were performed within the first 4 weeks from the onset of the symptoms in 27 patients with acute onset of dilated cardiomyopathy, with a dramatically decrease as the time passed (70\% within 3 months, then 38\%) [42]. This concept has been taken up by 2007 AHA/American College of Cardiology/ESC scientific statement on the role

Table 1 Indication to endomyocardial biopsy based on a recent international expert consensus document on myocarditis

Expert consensus document on management of AM and Infl-CMP Ammirati et al. $[4 \bullet \bullet]$

*Acute myocarditis presenting with cardiogenic shock (i.e., fulminant myocarditis)/acute HF, ventricular arrhythmias, or high-degree atrioventricular block, especially in case of non/mildly dilated left ventricle and recent onset of symptoms $(<1$ month)

*Myocarditis in the setting of immune checkpoint inhibitors therapy where the appropriate diagnosis has implications for the patient receiving additional cancer therapy and accuracy of cardiac magnetic resonance imaging for diagnosis is not known

*Acute myocarditis or hypokinetic dilated or non-dilated cardiomyopathy suspected for chronic inflammatory cardiomyopathy with persistent/relapsing release of myocardial necrosis markers, especially if associated with suspected/known autoimmune disorders or ventricular arrhythmias or II/III-degree atrioventricular block for therapeutic implications

*Acute myocarditis or chronic inflammatory cardiomyopathy associated with peripheral eosinophilia
ESC/HFSA/JHFS position statement on EMB - indications for myocarditis

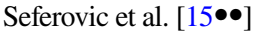

*Suspected fulminant myocarditis or acute myocarditis with acute HF, left ventricular dysfunction, and/or rhythm disorders

* High-degree atrioventricular block, syncope, and/or unexplained ventricular arrhythmias refractory to treatment, without obvious cardiac disease or with minimal structural abnormalities

*Suspected immune checkpoint inhibitors-mediated cardiotoxicity: acute $\mathrm{HF}$ with/without haemodynamic instability early after drug initiation ( first 4 cycles)

*Autoimmune disorders with progressive HF unresponsive to treatment with/without sustained ventricular arrhythmias and/or conduction abnormalities

*Dilated cardiomyopathy with recent-onset HF, moderate-to-severe left ventricular dysfunction, refractory to standard treatment 


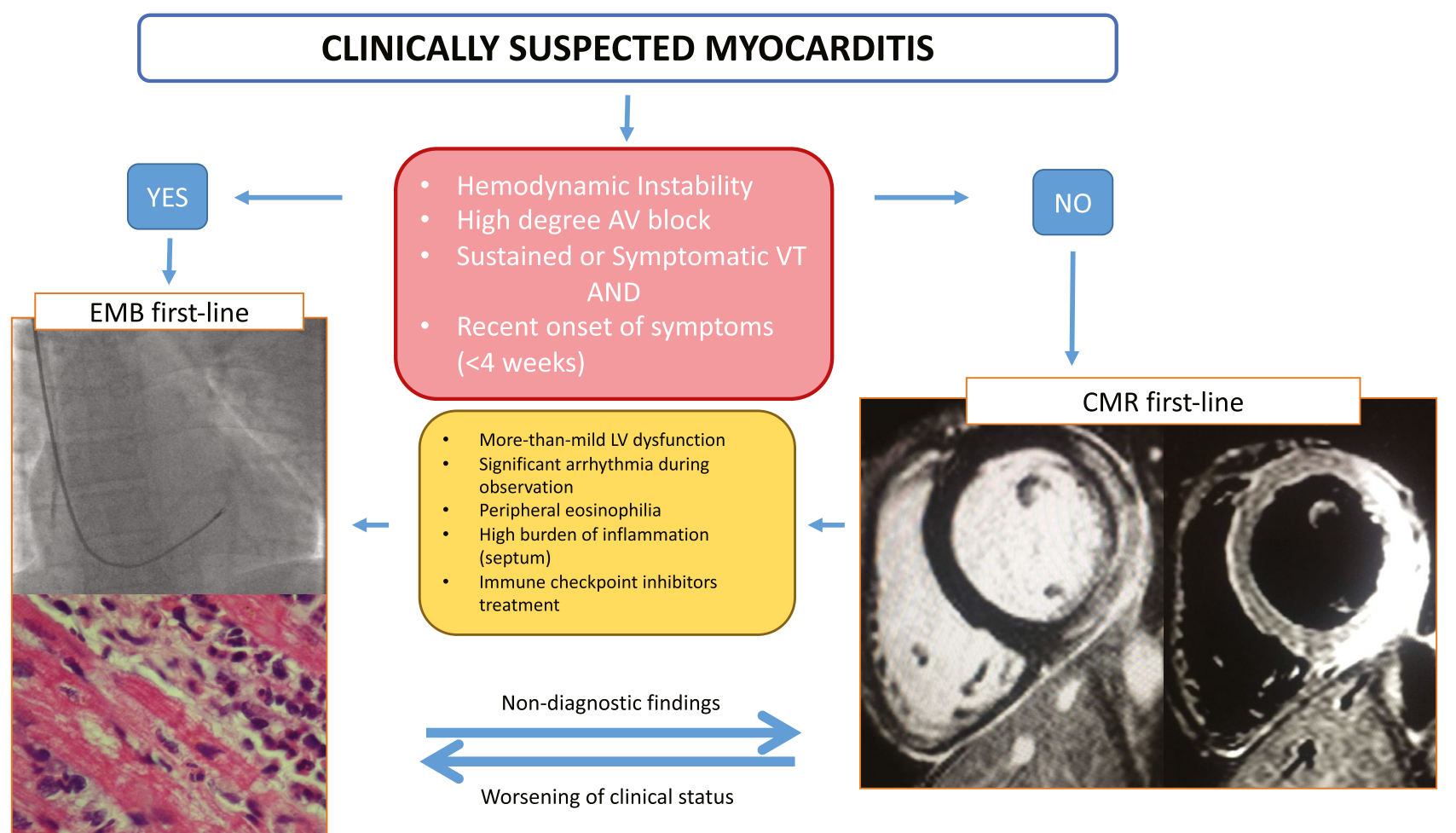

Fig. 2 Proposed diagnostic algorithm in patients with suspected acute myocarditis. The figure shows when an endomyocardial biopsy (EMB) should be the first-line exam and when cardiac magnetic resonance (CMR) should be the first-line exam. The images on the left show a fluoroscopic-guided biopsy, with evidence on histology of eosinophilic myocarditis remaking the unique value of biopsy that

of EMB in the management of the cardiovascular disease [43], as previously mentioned, and it has been confirmed in recent consensus documents $[4 \bullet \bullet, 30 \bullet \bullet, 32]$. Different diagnostic performances of EMB may be due to the presence of a more diffuse inflammatory infiltrate in the acute setting, whereas in chronic infl-CMP, infiltrates are sparse and a larger amount of fibrosis can be found, thus increasing the probability of a non-diagnostic EMB $[4 \bullet \bullet]$.

\section{How Much Do Technical Aspects Account for the Final Result?}

EMB is a non-targeted procedure which may increase the risk of false-negative results, especially when the disease is multifocal, focal, or localized [44, 45]. Adequate myocardial sampling with multiple specimens from different sites (guided by imaging techniques when indicated) is required to minimize the risk of a geographical miss in case of patchy myocardial involvement by the underlying disease process. According to the 2011 Consensus statement on EMB from the Association for European Cardiovascular Pathology and can determine the type of inflammatory infiltrate. On the right, CMR images show the extent of late gadolinium enhancement and edema on T2-weight short tau inversion recovery sequences. The advantage of CMR is providing a complete vision of the heart showing the extent and the localization of the inflammatory process. AV indicates atrioventricular; VT, ventricular tachycardia; LV, left ventricular

the Society for Cardiovascular Pathology at least three [46], preferably four, endomyocardial fragments, each of 1-2 mm in size should be sampled and immediately fixed in $10 \%$ buffered formalin at room temperature for light microscopic examination. To optimize the diagnostic accuracy of EMB, additional samplings are recommended in case of expected focal myocardial lesions. In addition, the same authors suggest that two fragments (or one if greater than $3 \mathrm{~mm}$ ) should be snap-frozen or preserved in RNA-later for virus molecular investigation if a viral myocarditis is suspected.

Recently, new tools to guide EMB have been tested, including electroanatomic mapping (EAM) [47-49], while new bioptomes to perform EMB during CMRI are currently under investigation [50]. The main reason for the enhanced sensitivity of EAM-guided EMB is linked to the identification of diseased myocardium based on low-voltage areas and abnormal electrograms on electroanatomic maps, thus increasing the likelihood of drawing diagnostic samples and reducing the number of biopsies. Indeed, in a recent singlecenter retrospective study that enrolled 162 consecutive patients submitted to EMB, EAM proved to be an excellent tool to guide EMB because of its sensitivity and specificity 
in identifying myocardial pathological substrates [49]. In this study, EAM showed an accuracy comparable to CMRI, with the combination of EAM-guided EMB and CMRI providing a positive predictive value of $89 \%$ on EMB. Nonetheless, EAM-guided EMB was not superior to CMRI in identifying patients with myocarditis, although it detected abnormalities in a small subset with negative CMRI and chronic myocarditis with ventricular arrhythmias [49]. Similarly, the execution of EAM-guided EMB in competitive athletes with ventricular arrhythmias and an apparently normal heart allowed the identification of a pathological substrate in $100 \%$ of cases with myocarditis diagnosed in 53\% of subjects [51]. EAM guidance can significantly increase EMB diagnostic yield over conventional fluoroscopy-guided biopsy in patients with ventricular arrhythmias and suspected myocarditis, even if no prospective trials are available [48]. Accordingly, EAM-guided EMB should be considered when both EAM and EMB are indicated to assess the electrical and pathological substrate, either for diagnostic or therapeutic purposes. On the other hand, technical considerations prevent EAM-guided EMB for routine diagnosis of myocarditis due to the costs and the time needed for EAM procedure. However, it should also be emphasized that EAM-guided EMB

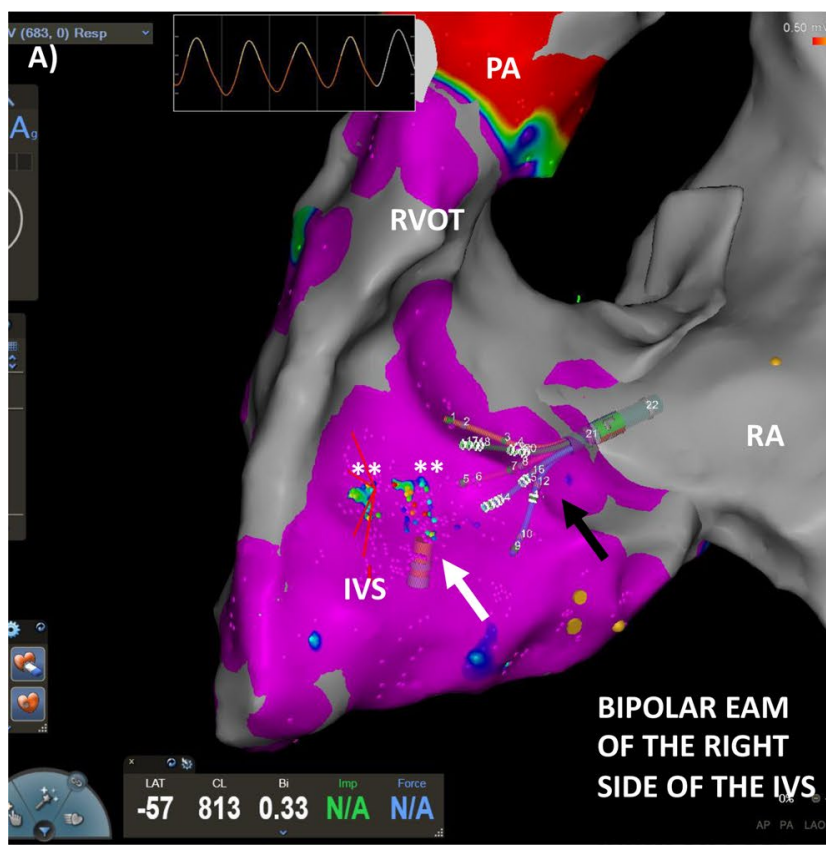

Fig. 3 Electroanatomic mapping (EAM)-guided endomyocardial biopsy (EMB) in a patient with suspected cardiac sarcoidosis. A Bipolar EAM by CARTO3® system and high density mapping PentaRay® (black arrow, Biosense Webster ${ }^{\circledR}$ ) of the right side of the interventricular septum (IVS), where healthy myocardium with a signal $>1.5 \mathrm{mV}$ is depicted in violet. Focal pathologic areas with decreased voltages are found in the middle of the IVS (** greenblue signal $<1.5 \mathrm{mV}$ ). Modified biopsy forceps (Cordis ${ }^{\circledR}-$ white arrow) are visualized in the map and can identify the precise point where performing EMB. B Fluoroscopic visualization (anteroposte- represents an important research tool to further define the role of myocardial inflammation in the pathogenesis of inherited and acquired arrhythmic conditions [52]. EAM-guided EMB could theoretically increase the diagnostic accuracy of EMB in cases of suspected cardiac sarcoidosis, granulomatous myocarditis with the known patchy myocardial disorder (Fig. 3) [53, 54]. In conclusion, EAM-guided EMB is an emerging albeit costly tool that could be considered especially in suspected focal myocarditis associated with a ventricular arrhythmic burden.

\section{Where Should EMB Be Performed: Right, Left, or Both the Ventricles?}

Traditionally, EMB has been obtained from the right ventricle (RV) via central venous access. Right internal right jugular and femoral vein are the most common access sites to perform RV-EMB, with jugular access preferred (Fig. 4A, B) [18•]; the femoral vein approach needs longer bioptomes within a long sheath. Given the stiffness of the sheath used for femoral biopsy, damage to the tricuspid valve or right atrial wall can occur. Samples are generally

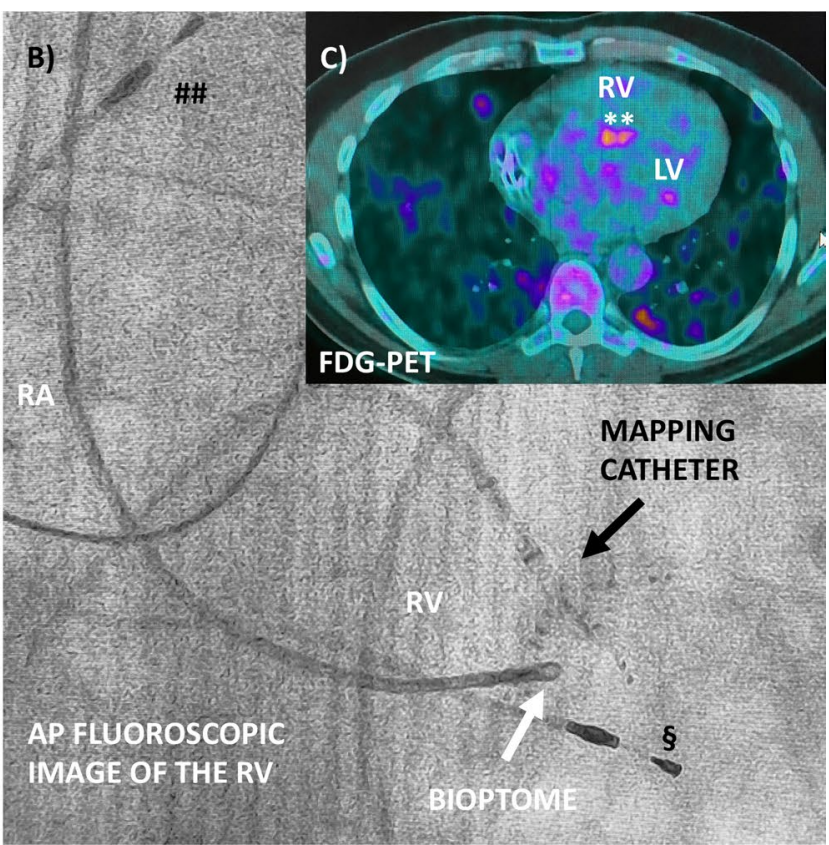

rior view) of the mapping catheter (black arrow) and biopsy forceps. \#\# Atrial pacing wire and $\S$ ventricular pacing wire in a patient with a permanent pacemaker. C Fluorodeoxyglucose positron emission tomography (FDG-PET) of the same patient shows a focal lesion in the middle of IVS suspected of granuloma. FDG-PET showed also several pulmonary lesions consistent with sarcoidosis. The patient presented a year before with a complete atrioventricular block. LV indicates left ventricle; IVS, interventricular septum; PA indicates pulmonary artery; RA, right atrium; RV, right ventricle; RVOT, right ventricular outflow tract 

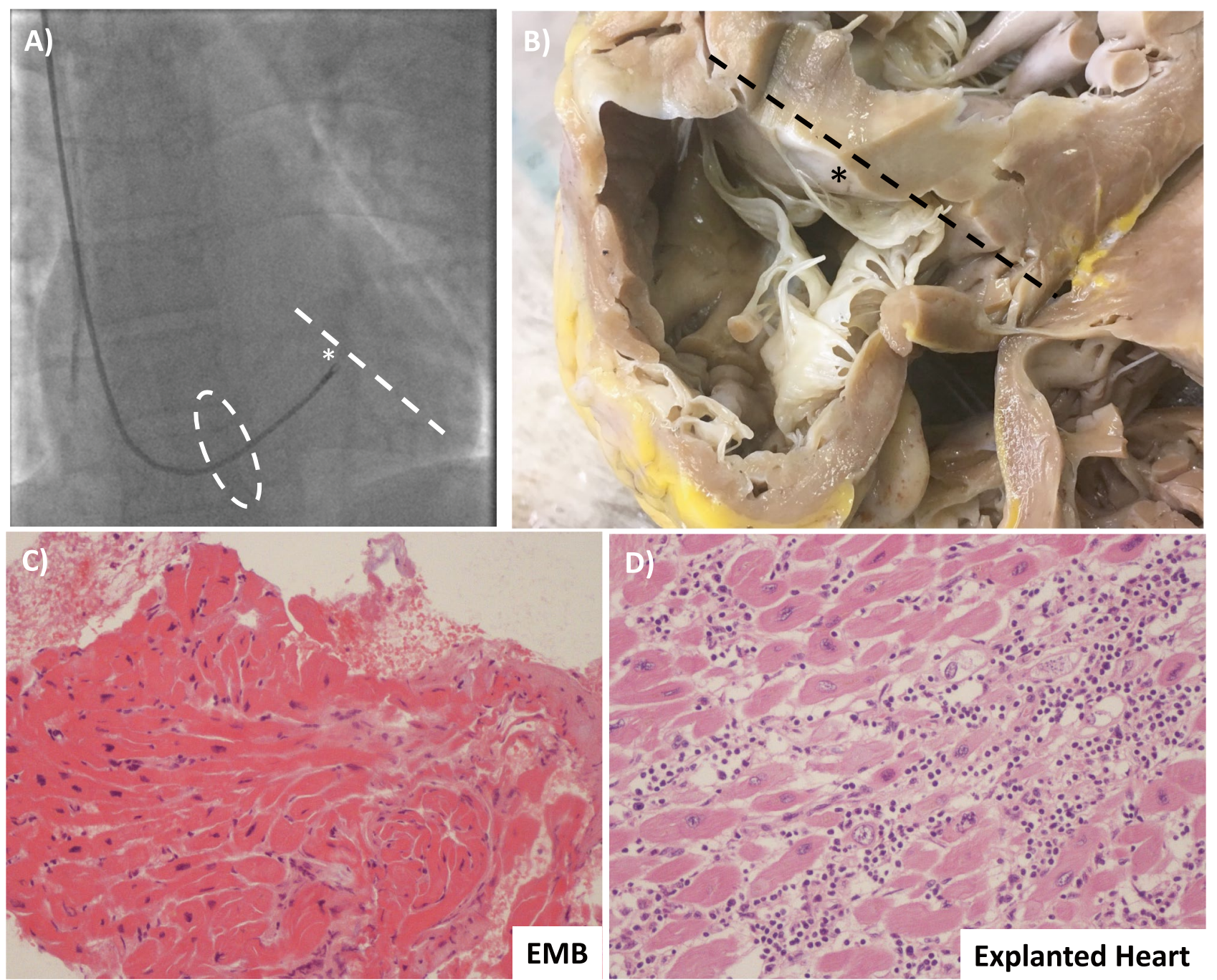

Fig. 4 Right ventricular endomyocardial biopsy (EMB). A Fluoroscopyguided biopsy from the right internal jugular vein. The bioptome passes the tricuspid valve (dashed oval) and reaches the ventricular septum (* and dashed line). B Explanted heart seen from the right ventricle of a patient with lymphocytic fulminant myocarditis shows the relationship between tricuspid valve and the ventricular septum (* and dashed line). Tricuspid chordal rupture can be a complication of biopsy from the right

obtained from the ventricular septum. Fluoroscopic guidance in combination with ECG monitoring is commonly used. Transeosophageal or transthoracic echocardiography can be an alternative to fluoroscopy. Ventricular ectopy or non-sustained ventricular tachycardia is observed when bioptome's jaws are in contact with the ventricular septum. Though RV biopsy is technically easier with less risk of adverse events, myocarditis frequently affects the LV in isolation [55]. A small study assessed the diagnostic yield of EMB on post-mortem hearts from patients with known lymphocytic myocarditis $(N=38)$. Biopsies were performed ex vivo and showed that the diagnostic yield of Dallas criteria was $63 \%$ from the RV and 55\% from the LV jugular vein. C From the same patient, the result of hematoxylin-eosin stain did not show an active myocarditis, while in $\mathbf{D}$ in the explanted heart an active lymphocytic myocarditis was demonstrated. This representative case underlines the false-negative results associated with biopsy due to the non-homogenous distribution of the inflammatory infiltrate and the potential sampling error

[26]. Although 10 specimens were obtained in each ventricle, the frequency of false-negative biopsies was $45 \%$ in the LV and 37\% in the RV. The authors concluded that the sampling error of EMB in patients with known lymphocytic myocarditis was mainly due to the focal nature of the inflammatory infiltrates or the involvement of regions that were inaccessible to the bioptome (i.e., mid and epicardial layers) (Fig. 4C, D). They also remarked that when myocarditis is evaluated by biopsy alone, only positive findings can be considered diagnostic [26]. In a similar study including 14 explanted hearts of patients with confirmed myocarditis, the false-negative rate was approximately $50 \%$ despite five bioptome-derived EMB of the ex vivo RV [25]. 
LV-EMB is usually performed through the right femoral artery, although radial access has been used [56]. In the femoral approach, a long guiding sheath is mounted over an angulated pigtail catheter that is used as a support during the positioning of the sheath [18•]. The bioptome is then slowly advanced against the cardiac wall outside the sheath to get the myocardial specimens (Fig. 5). Ischemic stroke and hemopericardium/tamponade are rare complications that can be associated with LV-EMB (reported in $0.64 \%$ in a large volume center) [57]. Yilmaz et al. [57] in a 2-center study assessed the respective diagnostic performance of $\mathrm{LV}, \mathrm{RV}$, and biventricular EMB in 481 patients with clinically suspected myocarditis. Almost all patients underwent CMRI before EMB, and myocardial samples were preferentially obtained from the ventricle showing late gadolinium enhancement (LGE). In particular, patients with LGE exclusively in the lateral LV free wall underwent LV-only or biventricular EMB, whereas patients with LGE in a septal wall or no LGE were submitted to RV-only or biventricular EMB. Biventricular EMB was diagnostic in a higher percentage of cases compared to selective singlechamber EMB $(71.1 \%$ vs $51.3 \%, p<0.001)$. Of note, patients in this series received a histologic diagnosis of myocarditis according to immunohistochemical and/or virologic findings and not based on Dallas criteria. When excluding the subset of patients in which only the presence of viral genome was detected, the difference between the biventricular and single-chamber approach remained significant $(56.9 \%$ vs $31.7 \%, p<0.001)$. Furthermore, the diagnosis of myocarditis would have been missed in $18.7 \%$ of cases when omitting the LV-EMB and in $7.9 \%$ of cases $(p=0.002)$ when omitting RV-EMB. Similar findings were reported by Chimenti and Frustaci [58], who retrospectively evaluated the diagnostic contribution and the risks of EMB in a large population including 4221 patients with clinically suspected myocarditis or non-ischemic cardiomyopathies. In this study, the decision to perform a biventricular EMB rather than an isolated RV-EMB or LV-EMB was based on various clinical and technical considerations, including involvement of a specific ventricular chamber on echocardiogram $(94.2 \%$ of cases showed a LV involvement, alone in $67 \%$ and in association with RV involvement in 26.9\%). Among the 706 patients diagnosed with myocarditis, a histologic and immunohistochemical diagnosis was evident in $95.7 \%$ of LV-EMB and in $54.2 \%$ of RV-EMB $(p<0.001)$ from patients with isolated LV echocardiographic involvement, whereas, in patients with associated echocardiographic RV involvement, the diagnostic yield of LV-EMB and RV-EMB was similar (96.6\% vs. 96.1\% respectively). Among unusual cases of isolated RV echocardiographic involvement, the diagnostic accuracy of RV-EMB was superior to LV-EMB (93\% vs $62.8 \%, p<0.001)$. In both studies, a very low rates of cardiac complications for LV-EMB (0.64\% and $0.33 \%)$ and RV-EMB $(0.82 \%$ and $0.45 \%)$ were reported. Other studies have found a cardiac complication rate of $1-2 \%$ at expert centers, that increases up to $8.9 \%$ at low-volume centers $[21 \bullet, 33 \bullet \bullet$. Interestingly in both studies $[57,58]$, the authors consider the higher diagnostic yield of the biventricular approach mainly related to the higher number of myocardial samples obtained, leading to a reduction of

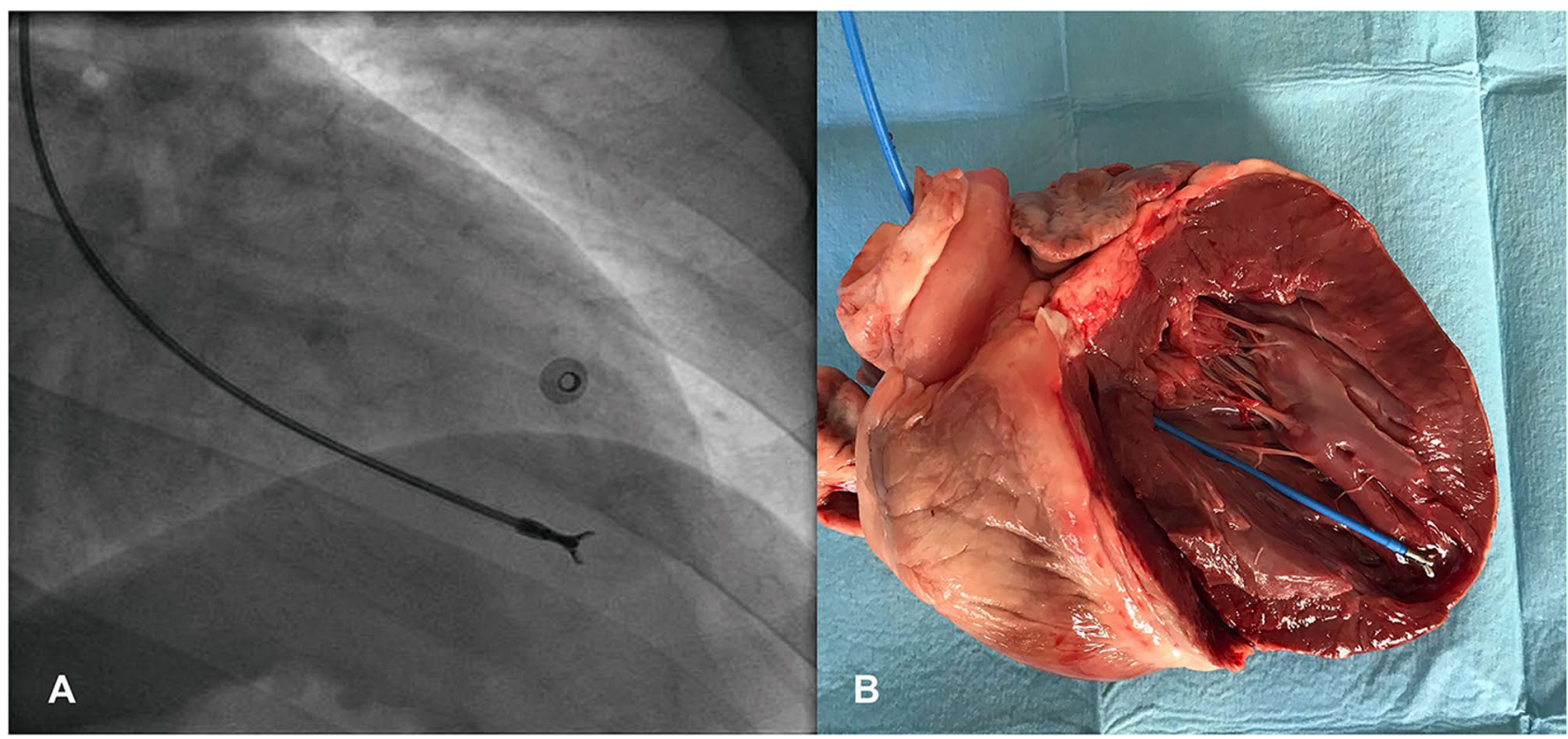

Fig. 5 Left ventricular endomyocardial biopsy (LV-EMB). A Fluoroscopy-guided LV-EMB in a patient with myocarditis. The bioptome is directed towards the septal-apical portion of the LV. B Visualization of the open bioptome in the LV of an explanted pig heart 
sampling error. A more recent study on 144 patients with myocarditis further supports the accuracy of RV-EMB in patients with CMRI-confirmed LV myocarditis [59]. Peretto et al. [59] found that RV-EMB sensitivity in patients with LGE involving both RV and ventricular septum, isolated $\mathrm{RV}$ or ventricular septum, and remote LV areas $(N=10$, 49 , and 67 cases) was not different with a 83.3, 84.4, and $90.5 \%$ diagnostic yield, respectively $(p=0.52)$. In this study, the sample size area of myocardial specimens was the only factor associated with RV-EMB sensitivity [59]. In conclusion, RV-EMB seems a reasonable approach in most cases of clinically suspected myocarditis. LV-EMB can be considered in experienced centers in cases where imaging suggests isolated LV involvement.

\section{Type of Inflammation: All Myocarditis Are Equally Detectable?}

The histological diagnosis of myocarditis includes different forms, classified according to the type of inflammatory cell that infiltrates the myocardium. The most common types are lymphocytic, eosinophilic, giant cell myocarditis (GCM), and granulomatous myocarditis (aka cardiac sarcoidosis). Their prevalence is different, for example, the lymphocytic subtype is reported to be the most frequent form, in about $70 \%$ of cases [28, 60••]. In contrast, eosinophilic [61], GCM [62], and cardiac sarcoidosis are relatively rare [63]. Myocarditis can be divided into two major clinical presentations: fulminant (characterized by rapid onset of hemodynamic instability requiring inotropes or mechanical circulatory supports) and non-fulminant. Histologically, fulminant myocarditis is generally associated with an extensive inflammatory infiltrate, with lymphocytic cells being the most common infiltrate. Of note, GCM is more frequent among patients with a fulminant presentation, estimated to account for approximately $10 \%$, while it is rarely seen as non-fulminant [60••]. For non-lymphocytic myocarditis, achieving histological proof by EMB is of utmost importance to rapidly start appropriate pharmacologic therapy. EMB's accuracy to identify the different types of myocarditis is strictly connected with the extent and distribution pattern presented by an inflammatory infiltrate: diffuse infiltration of the myocardium is associated with a higher rate of EMB sensitivity when compared to focal or patchy distributions [24•]. For this reason, EMB sensitivity is relatively low for the detection of lymphocytic myocarditis [25, 57]. EMB sensitivity for detecting cardiac sarcoidosis is also low, estimated to be around 20-30\%; this is most likely due to the focal nature of granulomas [64]. On the other hand, GCM is associated with high EMB sensitivity, with a reported range of 80-93\% [65]. Estimation of EMB accuracy in eosinophilic myocarditis is more difficult because a patchy interstitial myocardial eosinophilic and lymphocytic infiltrate may be present as well as a more severe diffuse form of necrotizing myocarditis, reflecting the wide spectrum of diseases in this group (hypersensitivity response to drugs or illness characterized by chronic hypereosinophilia, such as hypereosinophilic or

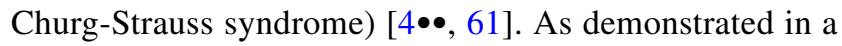
series of 69 patients with hypersensitivity eosinophilic myocarditis diagnosed at autopsy [66], the eosinophilic myocardial infiltrates ranged from mild to severe, and one-half of the cases had infiltrates with focal lesions that could be missed by EMB. Moreover, in this cohort, the histopathologic finding did not correlate with the severity of clinical symptoms or the incidence of sudden cardiac death. In conclusion, cardiac biopsy for myocarditis has high specificity and modest sensitivity for most forms. GCM, which is the subtype associated with the most severe forms of myocarditis and diffuse inflammatory infiltrates, can be detected with a high degree of accuracy by EMB.

\section{Analytic Methods Applied to the Samples: Does it Truly Increase Sensitivity?}

Developed during the 1980s, Dallas criteria have long represented the preferential method to reach the diagnosis of myocarditis. As such, most data concerning the diagnostic, prognostic, and therapeutic value of EMB are based exclusively on these criteria. However, the sensitivity of the Dallas criteria is relatively low [25, 26, 67]. Many interstitial cells may be difficult to characterize on routine hematoxylin and eosin-stained sections and normal components such as mast cells, fibroblast nuclei cut in cross-section, pericytes, histiocytes, and endothelial cells may resemble lymphocytes [68]. As demonstrated by several studies, viruses can be present and replicating in the myocardium without sufficient

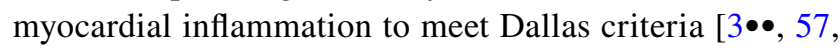
69]. Some authors consider that the presence of viruses in the myocardium without demonstration of inflammatory cells is a finding consistent with the definite diagnosis of myocarditis [69], though expert consensus documents do not

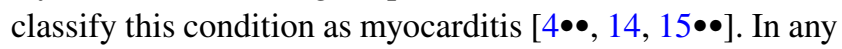
case, several experts regard the search for the viral genome as essential information to define the etiology of myocarditis [14]. In clinical practice, myocardial viral search in patients with AM is rarely performed [70, 71]. Furthermore, the most commonly detected virus is parvovirus B19 (PVB19), which is viewed by many investigators as a bystander without a definitive pathogenic role in myocarditis [72, 73]. The pathogenicity of enteroviruses may vary by age-while they are

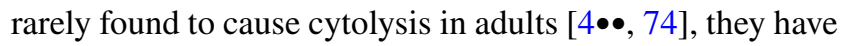
been found to definitively cause myocarditis in infants under 2 years of age [75]. 
Despite low sensitivity, histologic hematoxylin and eosin staining remains fundamental since it provides information concerning the presence and type of inflammatory infiltrate, the type of myocyte damage (myocytolysis, apoptosis, or other myocyte alteration), and the presence of fibrosis [76]. To overcome the low diagnostic yield of histologic processing, new criteria based on immunohistochemistry have been developed. Even though its use is still not standardized (proposed for the first time in the 1990s), immunohistochemistry can improve EMB sensitivity. Quantification of interstitial inflammatory cells consistent with active myocarditis is based on a cutoff threshold of $\geq 14$ leukocytes $/ \mathrm{mm}^{2}$ including up to 4 monocytes $/ \mathrm{mm}^{2}$ with the presence of CD3 positive T-lymphocytes $\geq 7$ cells $/ \mathrm{mm}^{2}[4 \bullet \bullet, 14,76]$. Even if not fully mentioned in the ESC 2013 position statement, the presence of myocardial necrosis should be recognized in association with immunohistochemistry findings. The antibodies that are mainly used are CD45 (leukocyte antigen common), CD3 (T cell marker), CD20 (B-lymphocytes marker), CD4 (helper T cell marker), CD8 (cytotoxic T cell marker), CD68 (macrophages marker), plus other stains to detect immune activation (i.e., HLA-DR) [4••, 14]. Immunohistochemical criteria seem to be particularly useful in chronic Infl-CMP; its application has improved the sensitivity to $40 \%$ for dilated cardiomyopathy [77]. Among 182 patients with dilated cardiomyopathies who underwent EMB, evidence of myocardial inflammation detected by immunohistochemistry (defined as an increased count of CD3 + T cells or CD68 + macrophages or CD163 + M2 macrophages) was associated with a poor prognosis [78]. Similarly, in 181 patients with suspected myocarditis the presence of increased inflammatory cells in the myocardium $\left(\geq 14\right.$ leucocytes $/ \mathrm{mm}^{2}$ plus positive stain for HLA-DR) was an independent predictor of outcome (cardiac death or heart transplant).

In the same study, viral genomes (comprising enteroviruses, PVB19, Epstein-Barr virus, and human herpesvirus type-6) in the myocardium were detected in $44 \%$ of patients but the presence of viral deoxyribonucleic acid (DNA)/ ribonucleic acid (RNA) was not associated with outcome [79]. These findings challenge the clinical utility of viral testing in myocarditis. Some experts still advocate that the detection of the viral genome should influence treatment strategy $[14,80,81]$. Since it is believed that a myocardial viral presence represents active infection, these authors argue that viral presence should be a contraindication to immunosuppressive treatment. Nevertheless, in the setting of $\mathrm{AM}$ and fulminant myocarditis, there is no evidence to support this statement $[31,70]$. In an analysis of 120 patients with fulminant lymphocytic myocarditis, there was no difference in outcomes or use of immunosuppressive therapies between 27 patients in whom a viral search was performed and 93 patients in whom it was not. In 5 out of $27(18.5 \%)$ patients, a virus was detected, and in all was a PVB19 [70]. Furthermore, a recent study suggests that immunosuppression does not affect PVB19 replication in the myocardium of patients with infl-CMP [82]. Thus, a reappraisal of the common term infectious myocarditis referring to the presence of viral genome in the myocardium should be considered [14]. In conclusion, while immunohistochemistry can increase the diagnostic sensitivity of EMB for the diagnosis of AM or infl-CMP, the detection of viral DNA/RNA in the myocardium without myocardial inflammation does not aid diagnosis. Further studies are needed to establish how high genome copies or replicative phase viruses impact the diagnosis of myocarditis. The statement by 2007 joined scientific statement on EMB is still valid: "because of uncertainties in the methods (for instance sampling errors and false-negative results), and interpretation at centers not experienced in these techniques, the consensus is that routine testing for viral genomes in EMB specimen is not recommended at this time outside of centers with extensive experience" [43]. Furthermore, there are investigational markers of inflammation and myocardial injury on histology, such as markers of cardiomyocyte apoptosis [83], and inflammatory activation in infiltrating leukocytes [84] that must be further assessed in prospective studies.

\section{Conclusions}

Myocarditis is a complex cardiac disease that can be associated with poor outcomes, especially in cases complicated by acute HF and ventricular arrhythmias $[60 \bullet \bullet, 85]$. While

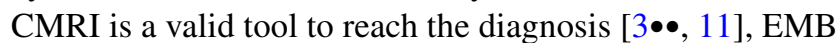
is the reference standard that provides definitive diagnosis along with other unique and timely information. EMB is of particular value in patients with acute clinical presentations $[3 \bullet \bullet, 4 \bullet \bullet, 15 \bullet \bullet]$, where rapid and effective treatment is needed. To optimize EMB diagnostic performance, it is important to keep in mind the different aspects that influence diagnostic yield, such as limiting EMB to patients with clinically suspected myocarditis and performing adequate sampling. Future studies will establish whether EAM-guided EMB can be routinely used and increase the rate of diagnosis compared with EMB and if viral genome detection can affect the diagnostic and therapeutic management.

Acknowledgements E.A. received a grant from the Italian Ministry of Health (GR-2019-12368506).

\section{Compliance with Ethical Standards}

Conflict of Interest E.D. Adler is a consultant for Abbott, Abiomed, AstraZenica, Endotronix, Ionis, Medtronic, and Novartis, and is on the board of directors of Genstem Therapeutics and shareholder of Rocket Pharmaceuticals. The other authors declare that they have no conflict of interest. 
Human and Animal Rights and Informed Consent This article does not contain any studies with human or animal subjects performed by any of the authors.

\section{References}

Papers of particular interest, published recently, have been highlighted as:

- Of importance

$\bullet$ Of major importance

1.- Ammirati E, Cipriani M, Moro C, Raineri C, Pini D, Sormani $\mathrm{P}$, et al. Clinical presentation and outcome in a contemporary cohort of patients with acute myocarditis. Circulation. 2018;138:1088-99. One of the largest multicenter clinical registry on acute myocarditis describing the outcome of these patiens.

2. Roth GA, Mensah GA, Johnson CO, Addolorato G, Ammirati E, Baddour LM, et al. Global burden of cardiovascular diseases and risk factors, 1990-2019: update from the GBD 2019 Study. J Am Coll Cardiol. 2020;76:2982-3021.

3.•• Tschope C, Ammirati E, Bozkurt B, Caforio ALP, Cooper LT, Felix SB, et al. Myocarditis and inflammatory cardiomyopathy: current evidence and future directions. Nat Rev Cardiol. 2021;18:169-93. Probably the current most influential review on myocarditis.

4.• Ammirati E, Frigerio M, Adler ED, Basso C, Birnie DH, Brambatti M, et al. Management of acute myocarditis and chronic inflammatory cardiomyopathy: an expert consensus document. Circ Heart Fail. 2020;13:e007405. A practical expert consensus document to guide diagnosis and treatment of myocarditis.

5. Mahmood SS, Fradley MG, Cohen JV, Nohria A, Reynolds KL, Heinzerling LM, et al. Myocarditis in patients treated with immune checkpoint inhibitors. J Am Coll Cardiol. 2018;71:1755-64.

6. Nguyen LS, Cooper LT, Kerneis M, Funck-Brentano C, Silvain J, Brechot N, et al. Systematic analysis of drug-associated myocarditis reported in the World Health Organization pharmacovigilance database. Nat Commun. 2022;13:25.

7. Poller W, Haas J, Klingel K, Kuhnisch J, Gast M, Kaya Z, et al. Familial recurrent myocarditis triggered by exercise in patients with a truncating variant of the desmoplakin gene. J Am Heart Assoc. 2020:e 015289. A case report of great interest that describes in details acute myocarditis associated with DSP truncating variant.

8. Piriou N, Marteau L, Kyndt F, Serfaty JM, Toquet C, Le Gloan $\mathrm{L}$, et al. Familial screening in case of acute myocarditis reveals inherited arrhythmogenic left ventricular cardiomyopathies. ESC Heart Fail. 2020;7:1520-33.

9. Artico J, Merlo M, Delcaro G, Cannata A, Gentile P, De Angelis $\mathrm{G}$, et al. Lymphocytic myocarditis: a genetically predisposed disease? J Am Coll Cardiol. 2020;75:3098-100.

10. Ammirati E, Veronese G, Cipriani M, Moroni F, Garascia A, Brambatti M, et al. Acute and fulminant myocarditis: a pragmatic clinical approach to diagnosis and treatment. Curr Cardiol Rep. 2018;20:114.

11. Ferreira VM, Schulz-Menger J, Holmvang G, Kramer CM, Carbone I, Sechtem U, et al. Cardiovascular magnetic resonance in nonischemic myocardial inflammation: expert recommendations. J Am Coll Cardiol. 2018;72:3158-76.
12. Francone M, Chimenti C, Galea N, Scopelliti F, Verardo R, Galea R, et al. CMR sensitivity varies with clinical presentation and extent of cell necrosis in biopsy-proven acute myocarditis. JACC Cardiovasc Imaging. 2014;7:254-63.

13. Bowman IA. Jean-Baptiste Senac and his treatise on the heart. Tex Heart Inst J. 1987;14:5-11.

14. Caforio AL, Pankuweit S, Arbustini E, Basso C, GimenoBlanes J, Felix SB, et al. Current state of knowledge on aetiology, diagnosis, management, and therapy of myocarditis: a position statement of the European Society of Cardiology Working Group on Myocardial and Pericardial Diseases. Eur Heart J. 2013;34:2636-48.

15.• Seferovic PM, Tsutsui H, McNamara DM, Ristic AD, Basso C, Bozkurt B, et al. Heart Failure Association of the ESC, Heart Failure Society of America and Japanese Heart Failure Society Position statement on endomyocardial biopsy. Eur J Heart Fail. 2021;23:854-71. A new consensus document on indication to EMB.

16. Aretz HT. Myocarditis: the Dallas criteria. Hum Pathol. 1987;18:619-24

17. Sakakibara S, Konno S. Endomyocardial biopsy. Jpn Heart J. 1962;3:537-43.

18. Francis R, Lewis C. Myocardial biopsy: techniques and indications. Heart. 2018;104:950-8. A well-written review on why and how to perform an EMB.

19. Holzmann M, Nicko A, Kuhl U, Noutsias M, Poller W, Hoffmann $\mathrm{W}$, et al. Complication rate of right ventricular endomyocardial biopsy via the femoral approach: a retrospective and prospective study analyzing 3048 diagnostic procedures over an 11-year period. Circulation. 2008;118:1722-8.

20. Elbadawi A, Elgendy IY, Ha LD, Mentias A, Ogunbayo GO, Tahir MW, et al. National trends and outcomes of endomyocardial biopsy for patients with myocarditis: from the National Inpatient Sample Database. J Card Fail. 2018;24:337-41.

21.• Singh V, Mendirichaga R, Savani GT, Rodriguez A, Blumer $\mathrm{V}$, Elmariah S, et al. Comparison of utilization trends, indications, and complications of endomyocardial biopsy in native versus donor hearts (from the Nationwide Inpatient Sample 2002 to 2014). Am J Cardiol. 2018;2018(121):356-63. Study showing the real-world indication to EMB and its complications.

22. Moslehi JJ, Brinkley DM, Meijers WC. Fulminant myocarditis: evolving diagnosis, evolving biology, evolving prognosis. J Am Coll Cardiol. 2019;74:312-4.

23. Van Linthout S, Tschope C. Viral myocarditis: a prime example for endomyocardial biopsy-guided diagnosis and therapy. Curr Opin Cardiol. 2018;33:325-33.

24. van der Boon RMA, den Dekker WK, Meuwese CL, Lorusso R, von der Thusen JH, Constantinescu AC, et al. Safety of endomyocardial biopsy in new-onset acute heart failure requiring venoarterial extracorporeal membrane oxygenation. Circ Heart Fail. 2021;14:e08387. Original article on the risk and potential benefit of EMB in patients with cardiogenic shock supported by VA-ECMO.

25. Chow LH, Radio SJ, Sears TD, McManus BM. Insensitivity of right ventricular endomyocardial biopsy in the diagnosis of myocarditis. J Am Coll Cardiol. 1989;14:915-20.

26. Hauck AJ, Kearney DL, Edwards WD. Evaluation of postmortem endomyocardial biopsy specimens from 38 patients with lymphocytic myocarditis: implications for role of sampling error. Mayo Clin Proc. 1989;64:1235-45.

27. Baccouche H, Mahrholdt H, Meinhardt G, Merher R, Voehringer M, Hill S, et al. Diagnostic synergy of non-invasive cardiovascular magnetic resonance and invasive endomyocardial biopsy in troponin-positive patients without coronary artery disease. Eur Heart J. 2009;30:2869-79. 
28. Ammirati E, Veronese G, Bottiroli M, Wang DW, Cipriani M, Garascia A, et al. Update on acute myocarditis. Trends Cardiovasc Med. 2021;31:370-9.

29. Ammirati E, Cipriani M, Lilliu M, Sormani P, Varrenti M, Raineri C, et al. Survival and left ventricular function changes in fulminant versus nonfulminant acute myocarditis. Circulation. 2017;136:529-45.

30.• Kociol RD, Cooper LT, Fang JC, Moslehi JJ, Pang PS, Sabe MA, et al. Recognition and initial management of fulminant myocarditis: a scientific statement from the American Heart Association. Circulation. 2020:CIR0000000000000745. Recent American Scientific Statement on management of patients with fulminant myocarditis.

31. Veronese G, Ammirati E, Chen C, Klingel K, Suzuki M, Okumura T, et al. Management perspectives from the 2019 Wuhan international workshop on fulminant myocarditis. Int J Cardiol. 2021;324:131-8.

32. Bozkurt B, Colvin M, Cook J, Cooper LT, Deswal A, Fonarow $\mathrm{GC}$, et al. Current diagnostic and treatment strategies for specific dilated cardiomyopathies: a scientific statement from the American Heart Association. Circulation. 2016;134:e579-646.

33.• Bennett MK, Gilotra NA, Harrington C, Rao S, Dunn JM, Freitag TB, et al. Evaluation of the role of endomyocardial biopsy in 851 patients with unexplained heart failure from 2000-2009. Circ Heart Fail. 2013;6:676-84. A study that evaluates the role and the diagnostic yield of EMB in patients with unexplained heart failure.

34. Sinagra G, Anzini M, Pereira NL, Bussani R, Finocchiaro G, Bartunek J, et al. Myocarditis in clinical practice. Mayo Clin Proc. 2016;91:1256-66.

35. Shauer A, Gotsman I, Keren A, Zwas DR, Hellman Y, Durst R, et al. Acute viral myocarditis: current concepts in diagnosis and treatment. MAJ. 2013;15:180-5.

36. Group JCSJW. Guidelines for diagnosis and treatment of myocarditis (JCS 2009): digest version. Circ J. 2011;75:734-43.

37. Hazebroek MR, Everaerts K, Heymans S. Diagnostic approach of myocarditis: strike the golden mean. Neth Heart J. 2014;22:80-4.

38. Inciardi RM, Lupi L, Zaccone G, Italia L, Raffo M, Tomasoni D, et al. Cardiac involvement in a patient with coronavirus disease 2019 (COVID-19). JAMA Cardiol. 2020;5:819-24.

39. Larson KF, Ammirati E, Adler ED, Cooper LT, Hong KN, Saponara G, et al. Myocarditis after BNT162b2 and mRNA1273 Vaccination. Circulation. 2021;144:506-8.

40. Abbate A, Gavin J, Madanchi N, Kim C, Shah PR, Klein K, et al. Fulminant myocarditis and systemic hyperinflammation temporally associated with BNT162b2 mRNA COVID-19 vaccination in two patients. Int J Cardiol. 2021;340:119-21.

41. Cooper LT Jr. Myocarditis. N Engl J Med. 2009;360:1526-38.

42. Dec GW Jr, Palacios IF, Fallon JT, Aretz HT, Mills J, Lee DC, et al. Active myocarditis in the spectrum of acute dilated cardiomyopathies. Clinical features, histologic correlates, and clinical outcome. N Engl J Med. 1985;312:885-90.

43. Cooper LT, Baughman KL, Feldman AM, Frustaci A, Jessup M, $\mathrm{Kuhl} \mathrm{U}$, et al. The role of endomyocardial biopsy in the management of cardiovascular disease: a scientific statement from the American Heart Association, the American College of Cardiology, and the European Society of Cardiology. Endorsed by the Heart Failure Society of America and the Heart Failure Association of the European Society of Cardiology. J Am Coll Cardiol. 2007;50:1914-31.

44. Billingham ME. Acute myocarditis: is sampling error a contraindication for diagnostic biopsies? J Am Coll Cardiol. 1989;14:921-2.

45. Baandrup U, Florio RA, Olsen EG. Do endomyocardial biopsies represent the morphology of the rest of the myocardium? A quantitative light microscopic study of single v. multiple biopsies with the King's bioptome. Eur Heart J. 1982;3:171-8.

46. Leone O, Veinot JP, Angelini A, Baandrup UT, Basso C, Berry $\mathrm{G}$, et al. 2011 consensus statement on endomyocardial biopsy from the Association for European Cardiovascular Pathology and the Society for Cardiovascular Pathology. Cardiovasc Pathol. 2012;21:245-74.

47. Pieroni M, Dello Russo A, Marzo F, Pelargonio G, Casella M, Bellocci F, et al. High prevalence of myocarditis mimicking arrhythmogenic right ventricular cardiomyopathy differential diagnosis by electroanatomic mapping-guided endomyocardial biopsy. J Am Coll Cardiol. 2009;53:681-9.

48. Pieroni M, Notarstefano P, Ciabatti M, Nesti M, Martinese L, Liistro F, et al. Electroanatomic mapping-guided endomyocardial biopsy in patients with apparently idiopathic ventricular arrhythmias. Pacing Clin Electrophysiol. 2020;43:1028-38.

49. Casella M, Dello Russo A, Bergonti M, Catto V, Conte E, Sommariva E, et al. Diagnostic yield of electroanatomic voltage mapping in guiding endomyocardial biopsies. Circulation. 2020;142:1249-60.

50. Unterberg-Buchwald C, Ritter CO, Reupke V, Wilke RN, Stadelmann C, Steinmetz M, et al. Targeted endomyocardial biopsy guided by real-time cardiovascular magnetic resonance. J Cardiovasc Magn Reson. 2017;19:45.

51. Dello Russo A, Pieroni M, Santangeli P, Bartoletti S, Casella M, Pelargonio G, et al. Concealed cardiomyopathies in competitive athletes with ventricular arrhythmias and an apparently normal heart: role of cardiac electroanatomical mapping and biopsy. Heart Rhythm. 2011;8:1915-22.

52. Pieroni M, Notarstefano P, Oliva A, Campuzano O, Santangeli $\mathrm{P}$, Coll M, et al. Electroanatomic and pathologic right ventricular outflow tract abnormalities in patients with Brugada syndrome. J Am Coll Cardiol. 2018;72:2747-57.

53. Muser D, Santangeli P, Liang JJ, Castro SA, Magnani S, Hayashi $\mathrm{T}$, et al. Characterization of the electroanatomic substrate in cardiac sarcoidosis: correlation with imaging findings of scar and inflammation. JACC Clin Electrophysiol. 2018;4:291-303.

54. Vaidya VR, Abudan AA, Vasudevan K, Shantha G, Cooper LT, Kapa S, et al. The efficacy and safety of electroanatomic mapping-guided endomyocardial biopsy: a systematic review. J Interv Card Electrophysiol. 2018;53:63-71.

55. Frey N, Meder B, Katus HA. Left ventricular biopsy in the diagnosis of myocardial diseases. Circulation. 2018;137:993-5.

56. Gobel S, Schwuchow-Thonke S, Jansen T, Karbach S, Emrich $\mathrm{T}$, Gori T, et al. Safety of transradial and transfemoral left ventricular compared with transfemoral right ventricular endomyocardial biopsy. ESC Heart Fail. 2020. https://doi.org/10.1002/ ehf2.13006.

57. Yilmaz A, Kindermann I, Kindermann M, Mahfoud F, Ukena C, Athanasiadis A, et al. Comparative evaluation of left and right ventricular endomyocardial biopsy: differences in complication rate and diagnostic performance. Circulation. 2010;122:900-9.

58. Chimenti C, Frustaci A. Contribution and risks of left ventricular endomyocardial biopsy in patients with cardiomyopathies: a retrospective study over a 28 -year period. Circulation. 2013;128:1531-41.

59. Peretto G, Cappelletti AM, Spoladore R, Slavich M, Rizzo S, Palmisano A, et al. Right ventricular endomyocardial biopsy in patients with cardiac magnetic resonance showing left ventricular myocarditis. J Cardiovasc Med (Hagerstown). 2021;22:560-6.

60.• Ammirati E, Veronese G, Brambatti M, Merlo M, Cipriani M, Potena L, et al. Fulminant versus acute nonfulminant myocarditis in patients with left ventricular systolic dysfunction. J Am Coll Cardiol. 2019;74:299-311. Large international registry that 
assess the outcome and predictos of prognosis in patients with histologically proven fulminant myocarditis.

61. Brambatti M, Matassini MV, Adler ED, Klingel K, Camici PG, Ammirati E. Eosinophilic myocarditis: characteristics, treatment, and outcomes. J Am Coll Cardiol. 2017;70:2363-75.

62. Cooper LT, Jr., Berry GJ, Shabetai R. Idiopathic giant-cell myocarditis--natural history and treatment. Multicenter Giant Cell Myocarditis Study Group Investigators. N Engl J Med. 1997;336:1860-6.

63. Birnie DH, Kandolin R, Nery PB, Kupari M. Cardiac manifestations of sarcoidosis: diagnosis and management. Eur Heart J. 2017;38:2663-70.

64. Birnie DH, Nery PB, Ha AC, Beanlands RS. Cardiac sarcoidosis. J Am Coll Cardiol. 2016;68:411-21.

65. Kandolin R, Lehtonen J, Salmenkivi K, Raisanen-Sokolowski A, Lommi J, Kupari M. Diagnosis, treatment, and outcome of giant-cell myocarditis in the era of combined immunosuppression. Circ Heart Fail. 2013;6:15-22.

66. Burke AP, Saenger J, Mullick F, Virmani R. Hypersensitivity myocarditis. Arch Pathol Lab Med. 1991;115:764-9.

67. Baughman KL. Diagnosis of myocarditis: death of Dallas criteria. Circulation. 2006;113:593-5.

68. Linder J, Cassling RS, Rogler WC, Wilson JE, Markin RS, Sears $\mathrm{TD}$, et al. Immunohistochemical characterization of lymphocytes in uninflamed ventricular myocardium. Implications for myocarditis. Arch Pathol Lab Med. 1985;109:917-20.

69. Pauschinger M, Phan MD, Doerner A, Kuehl U, Schwimmbeck PL, Poller W, et al. Enteroviral RNA replication in the myocardium of patients with left ventricular dysfunction and clinically suspected myocarditis. Circulation. 1999;99:889-95.

70. Veronese G, Ammirati E, Brambatti M, Merlo M, Cipriani M, Potena L, et al. Viral genome search in myocardium of patients with fulminant myocarditis. Eur J Heart Fail. 2020;22:1277-80.

71. Ammirati E, Varrenti M, Veronese G, Fanti D, Nava A, Cipriani $\mathrm{M}$, et al. Prevalence and outcome of patients with acute myocarditis and positive viral search on nasopharyngeal swab. Eur $\mathbf{J}$ Heart Fail. 2021;7:1242-5.

72. Verdonschot J, Hazebroek M, Merken J, Debing Y, Dennert R, Brunner-La Rocca HP, et al. Relevance of cardiac parvovirus B19 in myocarditis and dilated cardiomyopathy: review of the literature. Eur J Heart Fail. 2016;18:1430-41.

73. Nielsen TS, Hansen J, Nielsen LP, Baandrup UT, Banner J. The presence of enterovirus, adenovirus, and parvovirus B19 in myocardial tissue samples from autopsies: an evaluation of their frequencies in deceased individuals with myocarditis and in non-inflamed control hearts. Forensic Sci Med Pathol. 2014;10:344-50.
74. Badorff C, Lee GH, Lamphear BJ, Martone ME, Campbell KP, Rhoads RE, et al. Enteroviral protease 2A cleaves dystrophin: evidence of cytoskeletal disruption in an acquired cardiomyopathy. Nat Med. 1999;5:320-6.

75. Matsuura H, Ichida F, Saji T, Ogawa S, Waki K, Kaneko M, et al. Clinical features of acute and fulminant myocarditis in children2nd Nationwide Survey by Japanese Society of Pediatric Cardiology and Cardiac Surgery. Circ J. 2016;80:2362-8.

76. Richardson P, McKenna W, Bristow M, Maisch B, Mautner B, O'Connell J, et al. Report of the 1995 World Health Organization/International Society and Federation of Cardiology Task Force on the Definition and Classification of cardiomyopathies. Circulation. 1996;93:841-2.

77. Heymans S, Eriksson U, Lehtonen J, Cooper LT Jr. The quest for new approaches in myocarditis and inflammatory cardiomyopathy. J Am Coll Cardiol. 2016;68:2348-64.

78. Nakayama T, Sugano Y, Yokokawa T, Nagai T, Matsuyama TA, Ohta-Ogo K, et al. Clinical impact of the presence of macrophages in endomyocardial biopsies of patients with dilated cardiomyopathy. Eur J Heart Fail. 2017;19:490-8.

79. Kindermann I, Kindermann M, Kandolf R, Klingel K, Bultmann $\mathrm{B}$, Muller T, et al. Predictors of outcome in patients with suspected myocarditis. Circulation. 2008;118:639-48.

80. Sinagra G, Porcari A, Gentile P, Artico J, Fabris E, Bussani R, et al. Viral presence-guided immunomodulation in lymphocytic myocarditis: an update. Eur J Heart Fail. 2021;23:211-6.

81. Tschope C, Cooper LT, Torre-Amione G, Van Linthout S. Management of myocarditis-related cardiomyopathy in adults. Circ Res. 2019;124:1568-83.

82. Tschope C, Elsanhoury A, Schlieker S, Van Linthout S, Kuhl U. Immunosuppression in inflammatory cardiomyopathy and parvovirus B19 persistence. Eur J Heart Fail. 2019;21:1468-9.

83. Abbate A, Sinagra G, Bussani R, Hoke NN, Merlo M, Varma A, et al. Apoptosis in patients with acute myocarditis. Am J Cardiol. 2009;104:995-1000.

84. Toldo S, Kannan H, Bussani R, Anzini M, Sonnino C, Sinagra $\mathrm{G}$, et al. Formation of the inflammasome in acute myocarditis. Int J Cardiol. 2014;171:e119-21.

85. Anzini M, Merlo M, Sabbadini G, Barbati G, Finocchiaro G, Pinamonti B, et al. Long-term evolution and prognostic stratification of biopsy-proven active myocarditis. Circulation. 2013;128:2384-94.

Publisher's Note Springer Nature remains neutral with regard to jurisdictional claims in published maps and institutional affiliations. 